\title{
Accurate and easy method for systemin quantification and examining metabolic changes under different endogenous levels
}

(a) CrossMark

\author{
Victoria Pastor ${ }^{1 *} \mathbb{0}$, Paloma Sánchez-Bel ${ }^{1}$, Jordi Gamir² ${ }^{2}$ María J. Pozo ${ }^{2}$ and Víctor Flors ${ }^{1}$
}

\begin{abstract}
Background: Systemin has been extensively studied since it was discovered and is described as a peptidic hormone in tomato plants and other Solanaceae. Jasmonic acid and systemin are proposed to act through a positive feedback loop with jasmonic acid, playing synergistic roles in response to both wounding and insect attack. Despite its biological relevance, most studies regarding the function of systemin in defence have been studied via PROSYSTEMIN (PROSYS) gene expression, which encodes the propeptide prosystemin that is later cleaved to systemin (SYS). Interestingly, hardly any studies have been based on quantification of the peptide.

Results: In this study, a simple and accurate method for systemin quantification was developed to understand its impact on plant metabolism. The basal levels of systemin were found to be extremely low. To study the role of endogenous systemin on plant metabolism, systemin was quantified in a transgenic line overexpressing the PROSYS gene (PS+) and in a silenced antisense line (PS-). We evaluated the relevance of systemin in plant metabolism by analysing the metabolomic profiles of both lines compared to wildtype plants through untargeted metabolomic profiling. Compounds within the lignan biosynthesis and tyrosine metabolism pathways strongly accumulated in PS+ compared to wild-type plants and to plants from the PS - line. The exogenous treatments with SYS enhanced accumulation of lignans, which confirms the role of SYS in cell wall reinforcement. Unexpectedly, PS+ plants displayed wild-type levels of jasmonic acid (JA) but elevated accumulation of 12-oxo-phytodienoic acid (OPDA), suggesting that PS+ should not be used as an over-accumulator of JA in experimental setups.

Conclusions: A simple method, requiring notably little sample manipulation to quantify the peptide SYS, is described. Previous studies were based on genetic changes. In our study, SYS accumulated at extremely low levels in wild-type tomato leaves, showed slightly higher levels in the PROSYSTEMIN-overexpressing plants and was absent in the silenced lines. These small changes have a significant impact on plant metabolism. SA and OPDA, but not JA, were higher in the PROSYS-overexpressing plants.
\end{abstract}

\section{Background}

The welfare of consumers and the profits for farmers and producers through safe food production are increasing demands in society. These demands have led to a reduction in the use of chemical pesticides; alternative substitutions for pesticide includes activation of the plant

\footnotetext{
*Correspondence: pastorm@uji.es

${ }^{1}$ Associated Unit EEZ-UJ. Metabolic Integration and Cell Signaling Laboratory, Plant Physiology Section, Universitat Jaume I, Associated Unit to the CSIC, Castellón de la Plana, Castellón, Spain

Full list of author information is available at the end of the article
}

immune system and the reinforcement of defences [1-3], competition for the ecological niches of pests and microbial pathogens by beneficial microbes [4], or stimulation of the plant for antimicrobial secreted molecules to combat potential threats [5].

Cell signalling for defence is regulated through secreted molecules that can be perceived by external membranelocalized receptors. The perception of these molecules generates extracellular inputs that trigger downstream signalling outputs, which can in turn modulate cellular functions. In plants, specialized receptors constantly track putatively dangerous signals, which can stimulate

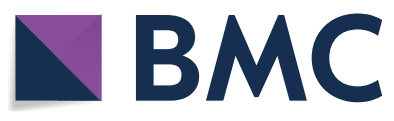

(c) The Author(s) 2018. This article is distributed under the terms of the Creative Commons Attribution 4.0 International License (http://creativecommons.org/licenses/by/4.0/), which permits unrestricted use, distribution, and reproduction in any medium, provided you give appropriate credit to the original author(s) and the source, provide a link to the Creative Commons license, and indicate if changes were made. The Creative Commons Public Domain Dedication waiver (http://creativecommons.org/ publicdomain/zero/1.0/) applies to the data made available in this article, unless otherwise stated. 
the immune response. This signalling initiates the cascade of defence reactions that can have a microbial origin, the so-called microbe-associated molecular pattern (MAMPs), or are generated in the host from damaged cells, known as the damage-associated molecular patterns (DAMPs). Both signals are present in the apoplast and are detected by the host via launch of Pathogen Associated Molecular Pattern-Triggered Immunity (PTI) [6]. An important group of DAMPs are secreted peptides, which function as key components of the immune system $[5,7,8]$. In fact, there is increasing interest in the role of peptides in development and defence processes [9]. For instance, several peptides produced by Arabidopsis thaliana, called AtPeps, and their receptors PEP-RECEPTOR 1 (PEPR1) and PEP-RECEPTOR 2 (PEPR2) have been recently described $[10,11]$. Moreover, a homologue of AtPeps, ZmPep1, was discovered in Zea mays [12], and its active peptide homologues displayed activities in different plant species against biotic stress [13].

The peptide systemin (SYS) was categorized as a hormonal peptide and was the first described in its class. Interestingly, 25 years after the discovery of this peptide [14], its properties, mechanism of action and post-translational changes driving its biosynthesis are still under study. In a search for systemic signals that accumulate after a predator attack, Pearce et al. [14] found a peptide that could induce proteinase inhibitor (PI) activity when supplied to young tomato plants in a manner similar to wounding or application of oligosaccharides and methyl jasmonate [15-17]. This peptide was found in phloem and systemic tissues within minutes after wounding and thus was called "systemin." SYS consists of a peptide sequence with 18 amino acids, which is generated by the proteolytic breakdown of the 200-amino acid protopeptide called PROSYSTEMIN [18]. Overexpression and antisense silencing of the PROSYS gene lead to constitutive expression or downregulation, respectively, of the plant defence gene PI $[18,19]$. Therefore, the study of SYS-regulated mechanisms is of great interest, particularly because more peptides have been isolated and identified as modulators of plant defence. The PROSYS gene seems to act together with HypSys precursor genes for effective systemic signalling and amplification of the octadecanoid pathway [20], supporting the idea that peptides cleaved from their respective precursors are important players in defence response.

SYS is classified as a ribosomal peptide because of its mode of synthesis [5]. The levels and function of these peptides are difficult to predict through transcriptomic studies due to their small size and, in some cases, the lack of a specific site of cleavage. Many peptide receptors remain elusive [21]. Therefore, the use of alternative methods to detect and/or identify these small peptides is important. Liquid chromatography coupled to mass spectrometry can be efficiently employed for peptide analysis. The number of recent publications identifying peptides in complex biological samples is rising [22-24], although there are still no reports of reliable peptide quantification in a plant matrix.

In the present study, we aimed to quantitatively determine the plant hormone peptide SYS with a simple method and with little manipulation of the plant sample. We have developed a very sensitive method to determine SYS in complex plant matrices at very low concentrations. An over-expressed mutant and an antisense mutant of PROSYSTEMIN $[18,19]$ were used as positive and negative controls, respectively. Previous studies demonstrated that changes in PROSYS expression could be extrapolated to real levels of SYS in the plant; however, likely post-translational regulation has previously been ignored, and real levels of the peptide in different experimental conditions remains mostly unknown.

A simple plant extraction and chromatographic procedure to determine the peptidic hormones is provided. This knowledge may also be useful in quantifying other plant peptides. Furthermore, regarding the relevance of SYS as a plant regulator, metabolomic studies in the overexpressor and antisense lines were performed. This study aimed to decipher pathways that are either regulated or influenced by SYS. Variations in the endogenous levels of SYS provide insight into the role of this peptide. Interestingly, higher impact of SYS variation is found in the synthesis of lignans, which are important compounds for cell wall formation and fortification of plant-basal defences and biotic stress $[25,26]$.

\section{Results and discussion}

\section{Optimization of an LC-MS/MS quantitative method for SYS determination}

SYS effects in tomato plants have been studied since the early 1990s [14], although quantitative studies of this peptide in plant tissues remain few. In this paper, a reliable method for the quantification of this peptide in tomato plant samples is proposed.

The Multiple Reaction Monitoring (MRM) procedure allows high specificity in the presence of complex sample matrices (such as plant extracts). This procedure can be achieved by selecting a specific precursor ion in the first quadrupole and then selecting a specific daughter fragment in the second quadrupole following fragmentation by the collision cell [27]. The total ion current of the SYS standard showed that the peptide eluted at 6.8 min (Fig. 1a), and the full scan MS spectrum of SYS showed the main signals at $\mathrm{m} / \mathrm{z} 503.5$ and 671.0 assigned to the $[\mathrm{SYS}+4 \mathrm{H}]^{4+}$ and $[\mathrm{SYS}+3 \mathrm{H}]^{3+}$ cations, respectively (Additional file 1: Fig. S1). Peptide precursor ion 

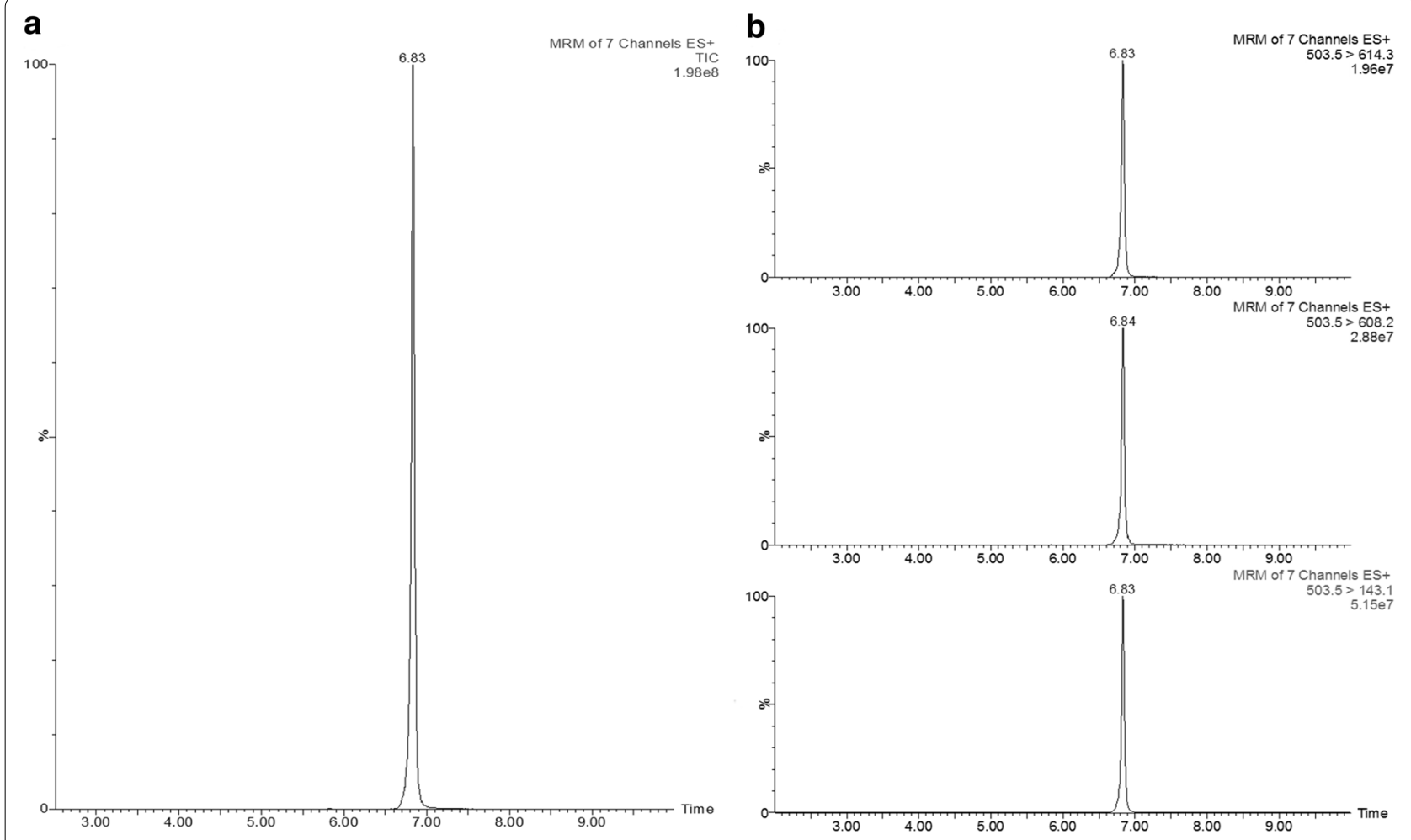

C
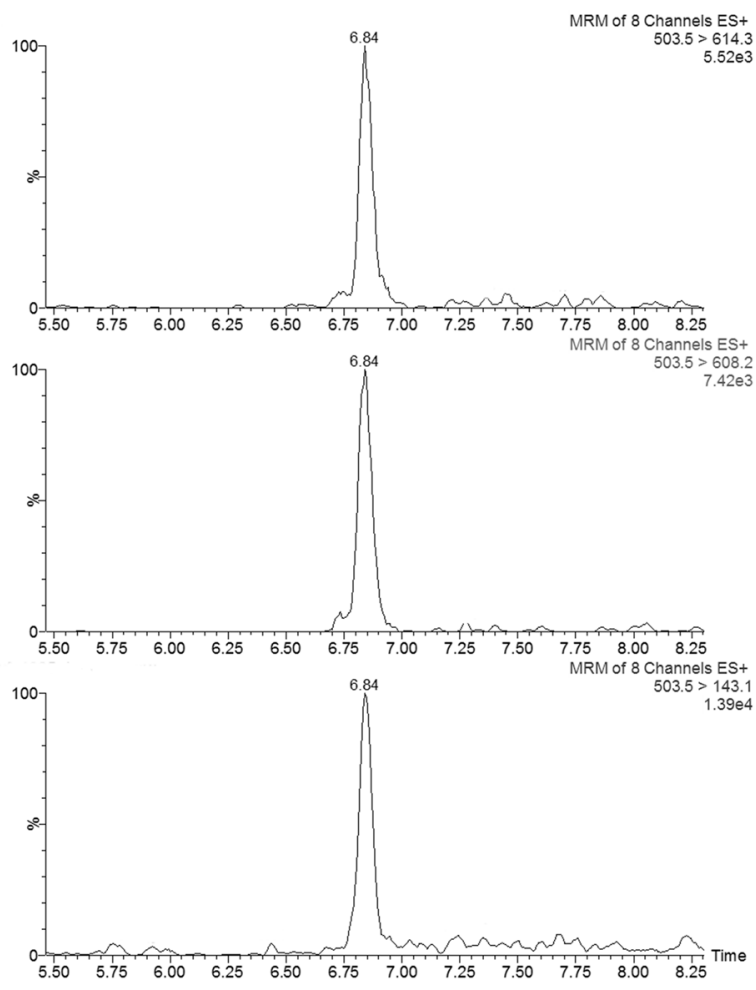

d
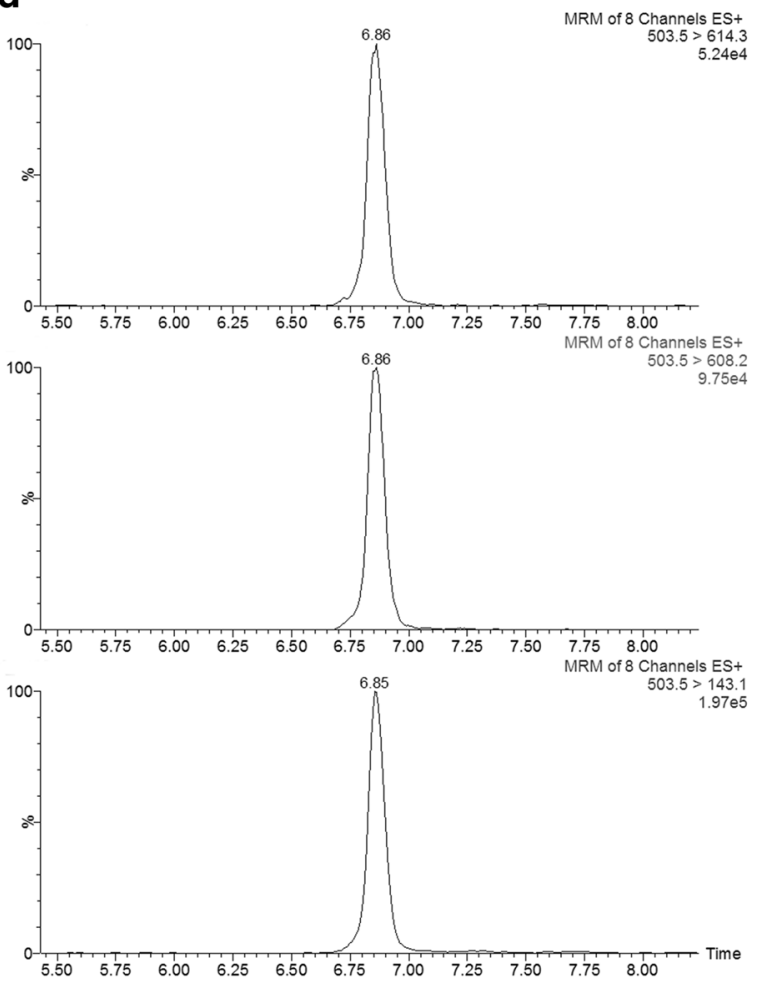

Fig. $1 \mathrm{HPLC}-M S / M S$ chromatograms for SYS in standard and plant samples. Main chromatograms obtained by $100 \mathrm{ng} \mathrm{ml}^{-1}$ of pure standard in $\mathrm{H}_{2} \mathrm{O}$ : ACN (9:1) v/V as both a total ion current of SYS in ESI (+) and $\mathbf{b}$ the three SRM transitions of the SYS standard. c SYS chromatogram for the three transitions obtained for SYS in the tomato plant sample and $\mathbf{d}$ the chromatogram for the same type of plant sample spiked with $150 \mathrm{ng} \mathrm{ml}^{-1}$ 
abundances were optimized by a full scan of SYS in $\mathrm{H}_{2} \mathrm{O}$ : $\operatorname{ACN}(9: 1) \mathrm{v} / \mathrm{v}$. The $[\mathrm{SYS}+4 \mathrm{H}]^{4+}(\mathrm{m} / \mathrm{z}$ 503.5) cation was considered in the present study because of its higher signal response with respect to $[\mathrm{SYS}+3 \mathrm{H}]^{3+}(\mathrm{m} / \mathrm{z}$ 671.0; Additional file 1: Fig. S1(a)).

MS/MS fragmentation of the $[\mathrm{SYS}+4 \mathrm{H}]^{4+}(\mathrm{m} / \mathrm{z} 503.5)$ was optimized to reach maximum ion abundances of products, and this optimization displayed fragment ions at $\mathrm{m} / \mathrm{z}$ 143.1, 608.2 and 614.3. Reasonably, the peaks obtained with these masses using the MRM detection elute at the same retention time provided an accurate tool for the identification of the peptide (Fig. 1b) and Additional file 1: Fig. S1(b)). To enhance reliability and accuracy of the method, the systemin heavy isotope $\left[{ }^{13} \mathrm{C}_{5},{ }^{15} \mathrm{~N}\right]$-SYS $\left(\mathrm{SYS}^{*}\right)$ was used as an internal standard. This approach ensured identical chromatographic behaviour and $\mathrm{m} / \mathrm{z}$ signal for the internal standard compared with the non-isotopic SYS. As the mass difference between the labelled and non-labelled SYS was more than two units in the parental ions and more than 5 units in some daughter ions, we avoided any possible overlapping due to natural isotopic abundance (Table 1b) [28]. For SYS*, the protonated [SYS* $+4 \mathrm{H}]^{4+}(\mathrm{m} / \mathrm{z} 505.0)$ was observed in its respective positive ESI mass spectrum, and the $505.0-148.1 \mathrm{~m} / \mathrm{z}$ transition was optimized and selected for quantification purposes (Additional file 2: Fig. S2). The cone voltage and collision energy values for SYS and SYS* are summarized in Table 1a. As expected, both standards showed the same retention times (Additional file 3: Fig. S3).

To quantify the peptide SYS, an HPLC-MS/MS method was validated regarding selectivity, linearity, precision, limit of detection (LOD) and quantification (LOQ), recovery and efficiency (Table 1a). LOD and LOQ has been evaluated based on building a calibration curve on the plant matrix of $P s$ - since the silenced plant lack or has not detectable levels of SYS. LOD has been calculated as $3.3 \times(\mathrm{SDy} /$ slope $)$ and LOQ by multiplying the same factor per 10 . The process efficiency has been determined by comparing plant material samples of $\mathrm{BB}(\mathrm{n}=6)$ spiked with the labelled standard before the extraction with a solution of pure labelled standard with a final concentration of $100 \mathrm{ng} \mathrm{ml}^{-1}$. This ratio is expressed in percentage. To improve peak resolution, as shown in Fig. 1c, SYS was detected in natural samples using all three selected transitions. Moreover, the transition corresponding to the internal standard was analysed in plant samples (BB, PS+ and Ps-) and there was no mass interference detected.

Moreover, the chromatographic retention and identity were confirmed by fortification of the natural sample with the commercial standard of SYS (Fig. 1d) in a concentration of $150 \mathrm{ng} \mathrm{ml}^{-1}$. Thus, the basal levels of SYS in the tomato plants could be quantified with very good sensitivity and accuracy. Among the many experiments performed to quantify SYS, and due to the natural variability of SYS, we observed variability in basal SYS levels, detecting very low levels in certain experiments, but they may fall below LOQ in others. Nevertheless, the sensitivity in our experiments was good enough for detecting small changes in the SYS concentration in response to environmental changes. Notably, we first analysed SYS using an Acquity TQD (www.waters.com) instrument, although it was not sensitive enough to even detect the standards at high concentrations in our experimental conditions. Accurate SYS quantification was only possible using a Xevo TQ-S instrument (www.waters.com). The extraction of SYS from tomato leaves was performed as shown in Fig. 2: $500 \mathrm{mg}$ of fresh material, stored at $-80{ }^{\circ} \mathrm{C}$, was homogenized in a tube with $2 \mathrm{ml}$ of Phenol/

Table 1 Optimized conditions for SYS quantification and method validation

\begin{tabular}{|c|c|c|c|c|c|c|}
\hline \multicolumn{7}{|l|}{ (a) } \\
\hline Compound & Weighted calibration equation & $\mathrm{R}^{2}$ & \multicolumn{2}{|c|}{$\begin{array}{l}\text { Precision (\%RSD) } \\
\text { Intra-day/Inter-day }\end{array}$} & $\%$ RE & $\%$ Efficiency \\
\hline Systemin & $y=1.11989 x-0.04709$ & 0.9945 & \multicolumn{2}{|c|}{$2.12 / 2.15$} & 97.73 & 99.23 \\
\hline \multicolumn{7}{|l|}{ (b) } \\
\hline Compound & Sequence & & $\operatorname{MRM}(\mathrm{m} / \mathrm{z})$ & Cone voltage (V) & & Collision energy $(\mathrm{eV})$ \\
\hline \multirow[t]{3}{*}{ SYSTEMIN } & \multirow[t]{3}{*}{ AVQSKPPSKRDPPKMQTD } & \multicolumn{2}{|r|}{$503.5>143.1$} & 35.0 & \multicolumn{2}{|r|}{14.0} \\
\hline & & \multicolumn{2}{|r|}{$503.5>608.2$} & 35.0 & \multicolumn{2}{|r|}{14.0} \\
\hline & & \multicolumn{2}{|r|}{$503.5>614.3$} & 35.0 & \multicolumn{2}{|r|}{14.0} \\
\hline SYSTEMIN* & A\{Val $(13 C 5,15 \mathrm{~N})\}$ AVQSKPPSKRDPPKMQTD & \multicolumn{2}{|r|}{$505.0>148.1$} & 35.0 & \multicolumn{2}{|r|}{14.0} \\
\hline
\end{tabular}

(a) Parameters of the calibration curve for SYS and parameters used for method validation. $R S D$ relative standard deviation; $R E$ recovery. $L O D\left(0.011 \mu \mathrm{g} \mathrm{I}^{-1}\right.$ ) and $\mathrm{LOQ}$ $\left(0.033 \mu \mathrm{g} \mathrm{ml}^{-1}\right)$ was calculated by signal to ratio noise of 3 and 10 respectively. A weighting factor of $1 / \mathrm{x}^{2}$ was applied to the curve

(b) Optimized MS/MS conditions for the analysis of SYS. Optimal conditions were selected by infusing the standards of SYS and SYS* to determinate appropriate cone and collision energies to obtain the characteristic transitions for each peptide 


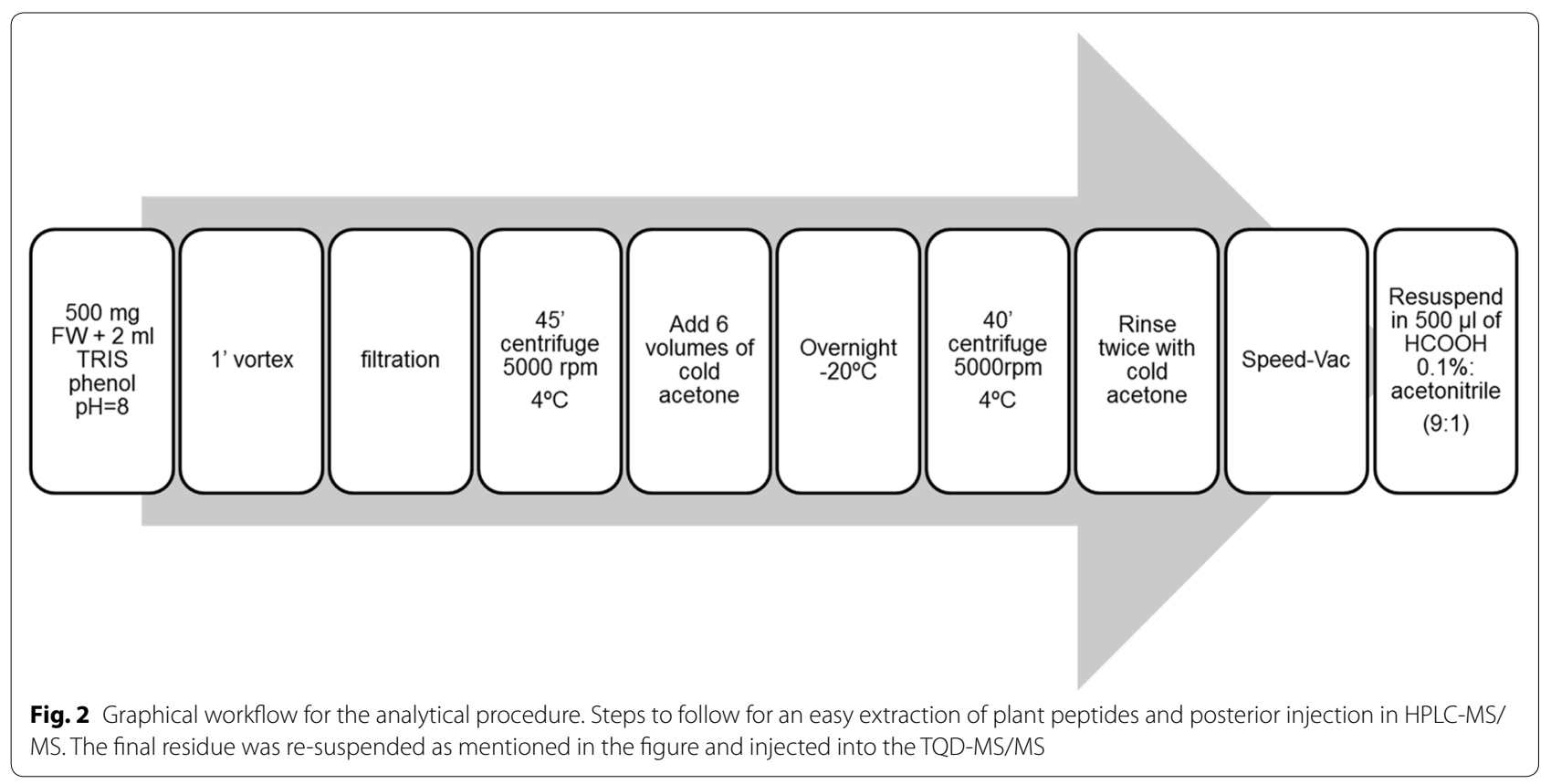

TRIS and saturated (ACROS Organic, ref. 327125000) at $\mathrm{pH}=8$. The mixed suspension was filtered by hydrophilic PVDF filter with a $25-\mathrm{mm}$ diameter and a pore size of $0.45 \mu \mathrm{m}$ (FILTER-LAB). After centrifugation, 6 volumes of pure cold acetone (Scharlau, AC0312, Pharm pur $^{\circledR}$ ) were added to each sample, and samples were kept overnight at in $-20^{\circ} \mathrm{C}$. The precipitate was recovered the next day and rinsed twice with cold acetone. The liquid phase was discarded, and the pellet was dried. The final residue was re-suspended in $500 \mu \mathrm{l}$ of a solution of $\mathrm{H}_{2} \mathrm{O}$ ( $\mathrm{HCOOH} 0.1 \%)$ : acetonitrile $(9: 1, \mathrm{v} / \mathrm{v})$ and injected into the TQS-MS/MS instrument.

Some tentative methods have been previously proposed for SYS detection [29, 30]. These methods are suitable for detection and quantification, although the manipulation of the sample is sensitive to possible degradation of the plant material. The QQQ (TQS) mass analyser used in our work was more suitable for quantification than the QTOF, with the latter being more accurate for exact mass measurement. Our method has two advantages. First, the handling proposed in the present method is simpler with no digestion step. By avoiding the digestion step, the coelution of peptides derived from the digestion reduced the signal-to-noise ratio and increased the background signal, thereby improving the sensitivity of the method. Second, the use of a labelled internal standard ensured accuracy and precision, moderating the matrix effect due to the complexity of the plant sample and avoiding losses during extraction [24].

\section{SYS levels in tomato PROSYSTEMIN antisense} and overexpressor lines

Pearce and colleagues described the presence of SYS in plants for the first time [14]. Surprisingly, an accurate method for SYS quantification is still not available, probably due to low basal levels of SYS in plants and the lack of appropriately sensitive instrumentation. PROSYS expression and/or responsive mutants were employed in this research to study the signals underpinning possible SYS effects in plants, such as its function as plant defence activator at the local or systemic level [31-33]. Several studies were performed using transgenic lines, which overexpressed or blocked the expression of PROSYS [33, 34]. Nevertheless, accurate quantification of shifts in SYS levels is still missing. In the present study, basal levels of SYS were determined using the wild-type plants of tomato BetterBoy (BB) cultivar and transgenic 35S::PROSYS (PS+) and antisense PROSYS (PS-) lines $[18,19]$. The basal levels of SYS could be quantified in the range of ng. $\mathrm{g}^{-1}$ of fresh weight (FW). The levels of SYS in the overexpressor line were twice the amounts found in wild-type plants and remained under the detection limits in PS- antisense plants (Fig. 3a). These results confirm the low in planta levels of this peptide, even in the overexpressing PS+ plants. McGurl and colleagues [19] showed a constitutive higher expression of PROSYS in transgenic plants than in the control, together with a systemic enhancement of the PI1 and PI2 genes. Interestingly, the basal levels 

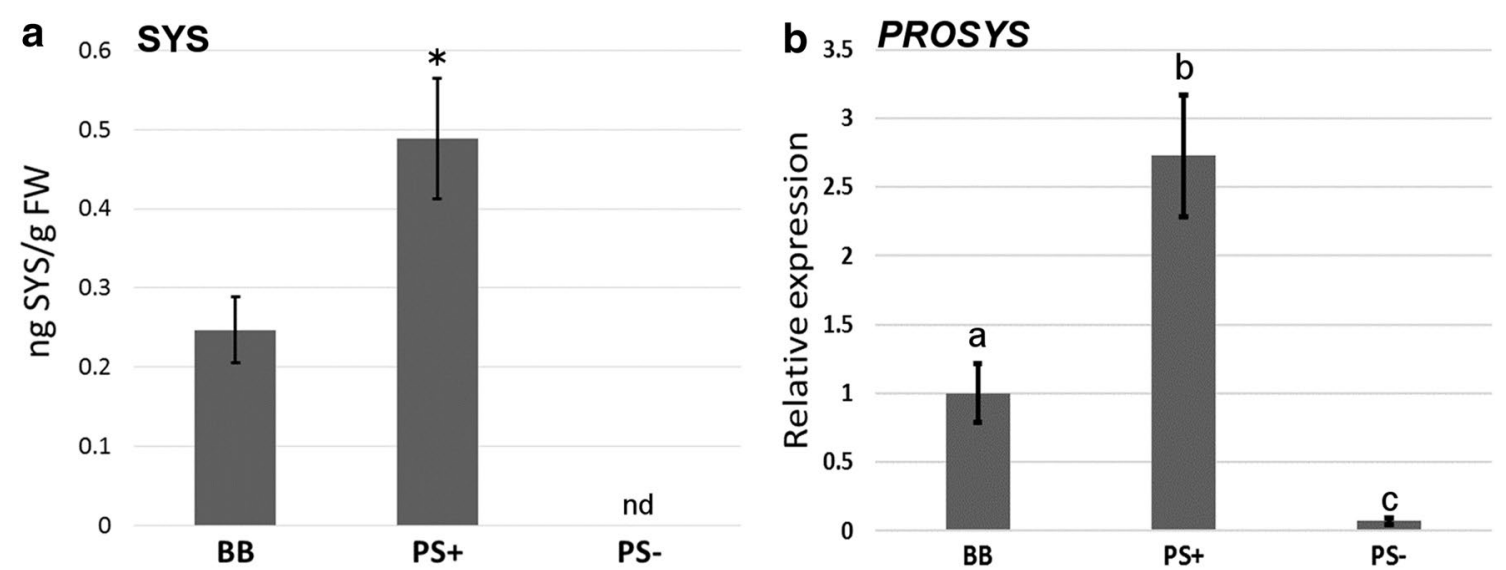

Fig. 3 Quantification of SYS and expression of the PROSYS gene in tomato leaves. Levels of $\mathbf{a}$ SYS peptide and $\mathbf{b}$ PROSYS gene expression in leaves of tomato plants in wild-type plants (BB), the overexpressor of PROSYS (PS+) and the antisense of PROSYS (PS-). Data represent the mean and standard deviation $(n=6)$. The experiment was repeated three times, and asterisks indicate significant differences as determined by Student's t-test, $a=0.05$. No detection represented by nd. Different letters indicate statistically significant differences (ANOVA, Fisher's least significant difference $($ LSD) test, $p>0.05, n=6)$

detected in wild-type plants were not enough to induce these systemic responses. Therefore, they proposed that PROSYS synthesis and subsequent processing to deliver SYS must be a regular process, but that SYS might remain compartmentalized until stress appears in wildtype plants. Thus, for overexpression, SYS delivered in the phloem may saturate the process, producing a continuous release of the peptide. However, SYS circulation may increase in wild-type plants only after wounding, inducing the transcription of proteinase inhibitors. As expected, the profile of SYS levels with respect to the expression levels of the PROSYS gene correlates (Fig. 3b). The basal amount of SYS found in PS+ plants was not as high as expected for an over-expressing line. This finding may suggest a strong post-translational regulation of the precursor's cleavage and transport to phloem, supporting the relevance for the development of simple methods for peptide quantification. A recent publication provides relevant information about the mechanisms regulating the SYS levels by PROSYS processing: Beloshistov and colleagues [35] identified two genes, Sl12g088760 and Sl04g078740, which encode for two phytaspases, named SlPhyt-1 and SlPhyt-2, respectively. These enzymes are aspartate-specific proteinases, which can hydrolyse the two aspartate residues flanking the SYS sequence in the precursor PROSYS leading to the cleavage of PROSYS into SYS. Undoubtedly, the evolution of this field is highly promising, particularly because the development of new analytical techniques can be suitable for the identification of post-translationally modified proteins $[27,36]$.

\section{SYS has a major impact in the plant metabolic profile}

Previously, the relevance of the high levels of PROSYS in plant defence responses was described with respect to wild-type plants. The impact of SYS in plant metabolism has been studied through a stimulus that increased expression of the PROSYS gene [33, 37]. Thus, we wondered whether the increased levels of SYS in plant tissues could significantly alter plant metabolism. To study the level and relevance of the impact of SYS in the metabolome, a comparative metabolic analysis of shoots of wild-type, PS+ and PS- plants was conducted. An untargeted analysis was performed using UHPLC coupled to a Q-TOF (quadrupole-time of flight) mass spectrometer. The analysis was carried out in both positive and negative electrospray ionization (ESI) modes to cover a wider spectrum of compounds under the influence of SYS. Metabolic and bioinformatic analyses of the signals obtained were performed following the procedure described by Fernie et al. [38], Kaever et al. [39], and Xia et al. [40]. Score 3D plots of a PLS (Fig. 4a) showed three major components contributing to separation of the three groups. In both ionization modes, a clear separation of the three conditions was observed, with $76 \%$ of the total components contributing to the differences in ESI (-), while $92.6 \%$ of the components may explain the variance among groups. This experiment was performed in the absence of stress, so the observed phenomena can be attributed only to the constitutive levels of SYS in the three different genotypes. Following a partial leastsquare (PLS) regression analysis, it was observed that the absence of SYS in PS- showed relevant differences 


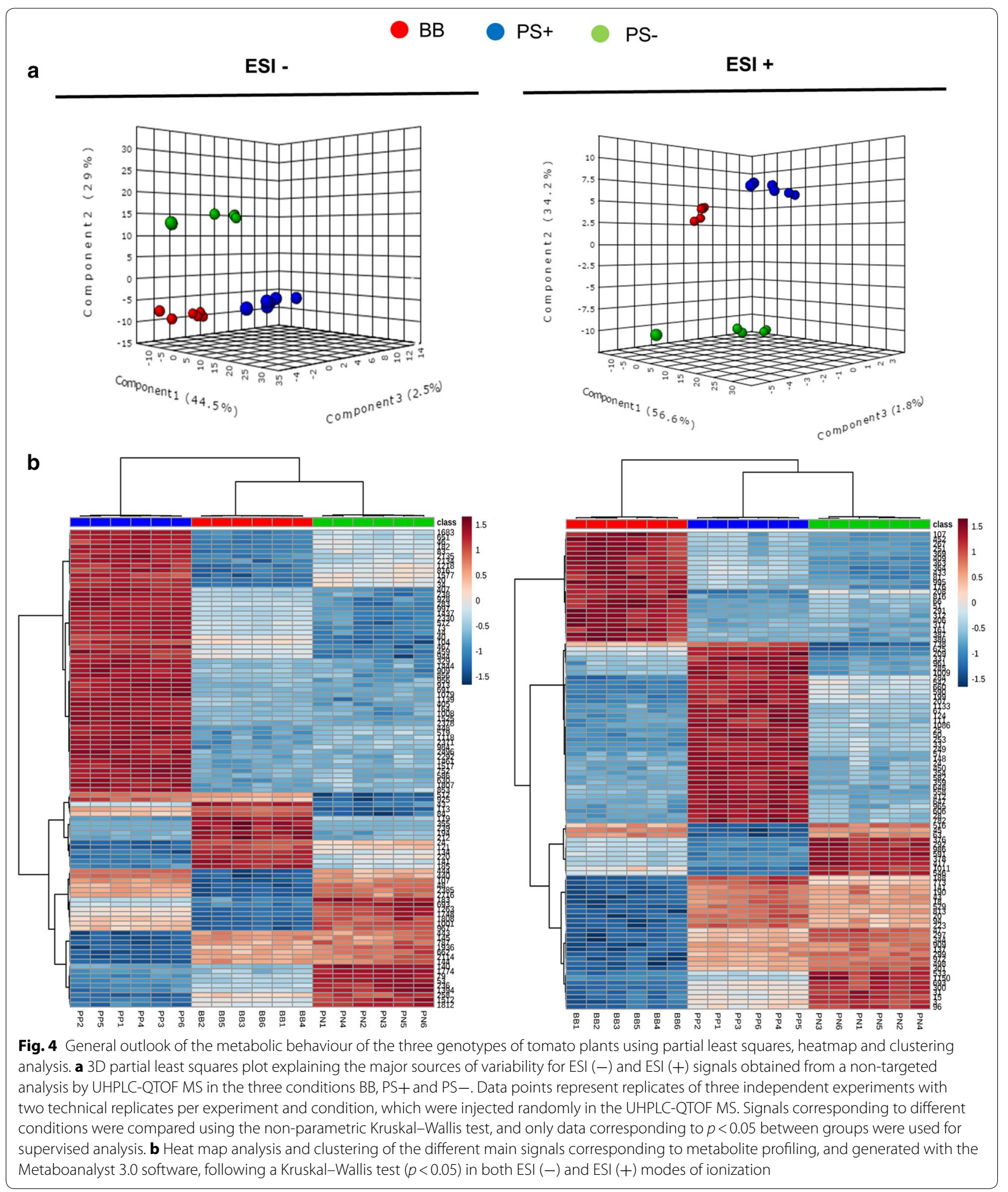

compared with the other two conditions (Fig. 4a; Additional file 5: Table S2). Although the three groups of samples were clearly separated, PS+and BB plants remained closer, while PS - showed a very different metabolic behaviour. The differences between the three conditions were visualized through supervised heatmaps 
(Kruskal-Wallis test, $p<0.05$ ). Figure $4 \mathrm{~b}$ shows the clustering and heatmap of those compounds with higher differences among all signals extracted following statistical analysis. Interestingly, in the negative mode, PS+ exhibited a higher number of accumulated compounds, while PS - and BB clustered together. In contrast, on ESI (+), PS+ and PS - clustered closely. Nevertheless, the signals in PS+ were still significantly different with respect to the other two conditions, demonstrating a strong influence of the SYS peptide in plant metabolism despite the low changes found in PS+ overexpressing plants. This finding concurs with the consideration of SYS as a peptidic hormone. It has been demonstrated that the expression of the tomato PROSYS gene in other plant species also has a major impact on the proteomic profile [41], highlighting the impact that SYS produces in plants, either at the metabolic, proteomic, or transcriptomic levels [33]. Notably, all studies $[33,41]$ were performed in the absence of stress.

\section{SYS has a major impact on the lignan and tyrosine metabolic pathways}

To elucidate the regulating/signalling function of the SYS peptide in plants, a study of the metabolic pathways was performed, considering the signals (metabolites) showing specific profiles of accumulation under the proposed conditions (BB, PS+and PS-). One of the challenges in non-targeted metabolic analysis is to identify the signals showing relevant changes in intensity. Using MarVis 2.0 [42] software, those metabolites with homogeneous behaviour among different experimental conditions, including BB, PS + and PS-, were grouped, assigned and associated with different metabolic pathways. Identification was performed at three different levels by a match in the exact mass, comparative fragmentation spectrum (Metlin (https://metlin.scripps.edu/), MassBank (http:// massbank.jp), and the Kegg Solanum lycopersicum databases, for pathway assignments [43] and retention times of the fragments using internal libraries.

We then focused on signals showing higher accumulation in PS+ plants to identify systemin-regulated metabolic processes. Following MarVis Pathway analysis [42], PS + plants showed a strong over-representation of metabolites within the lignan pathway (Additional file 4: Table S1). Lignans are an abundant class of phenylpropanoids defined as dehydrodimers of monolignols that are optically active and widely spread in the plant kingdom [44]. Monolignols are derived from phenylalanine (Phe) through several enzymatic reactions, including phenylalanine ammonia lyase (PAL) [25]. Endogenous SYS showed a major impact in the lignan and tyrosine pathways, among others (Table 2). Interestingly, the accumulation of lignans, stimulated by SYS, is preceded by a reduction
Table 2 Assignment of active metabolic pathways in PS+

\begin{tabular}{ll}
\hline ESI (-) $\mathbf{2 0 5}$ markers in $\mathbf{8 2}$ sets & ESI (+) $\mathbf{8 5}$ markers in $\mathbf{6 0}$ sets \\
\hline Lignans & Porphyrin and chlorophyll metabolism \\
Tyrosine metabolism & Ubiquinone and terpenoid-quinone \\
ABC transporters & biosynthesis \\
Flavonoid biosynthesis & Tyrosin metabolism \\
& $A B C$ transporters
\end{tabular}

Main metabolic pathways responsive to higher levels of SYS found in PS+ in both modes of ionization ESI (+) and ESI (-). MarVis Pathway package assigned the signals to metabolic pathways according to Solanum lycopersicum data base. Sets means all the pathways assigned by the software that can be implicated in systemin action

in their precursor compounds, such as caffeic and ferulic acids, originating from the phenylpropanoid biosynthesis pathway (Fig. 5). Precursor compounds showed a decrease in PS+, possibly leading to a higher synthesis of lignans in PS+ plants. Interestingly, some of these tentative lignans, such as pinoresinolin, taxiresinol and syringaresinol, were less accumulated in PS - plants, pointing out the relevance of the presence of SYS in the accumulation of these lignans. Similar profiles were observed for metabolites related to different pathways, such as tyrosine metabolism (Table 2; Additional file 5: Table S2) and were also found to be less represented in the antisense PS- plants (Additional file 5: Table S2). Tyrosine metabolism was detected in both, negative and positive ESI. This metabolic pathway might participate in the formation of lignans through the phenylpropanoid pathway, as described previously [25].

Another highly represented pathway in PS+ plants were the $\mathrm{ABC}$ transporters-substrates compound pathway (Table 2). These results suggest both an enhancement of the trafficking of metabolites in the plasma membrane and increased cellular communication, likely orchestrated by the peptide SYS $[45,46]$. Among the pathways affected by endogenous SYS, several compounds were selected that match the profile of being much higher in PS+ plants but much lower in PS- plants than in the control plants. Exact mass or exact mass and fragmentation spectrum were used for the identification of these compounds (Additional file 5: Table S2). The use of MarVis for identification has some limitations; this is because we only consider the annotated compounds as tentatively identified, and a full identification using pure standards, when available, would be desirable to fully characterise the identity of compounds altered by SYS in plants.

All these results strongly suggest that endogenous SYS participates in the reorganization of specific cell wall components in tomato plants which, in turn, may participate in cell wall reinforcement. Among the identified lignans, there are some glycosylated forms, possibly storage forms of lignans that may accumulate in vacuoles. The mode of lignan transport is still a subject of active research. Interestingly, in our study, one of the 


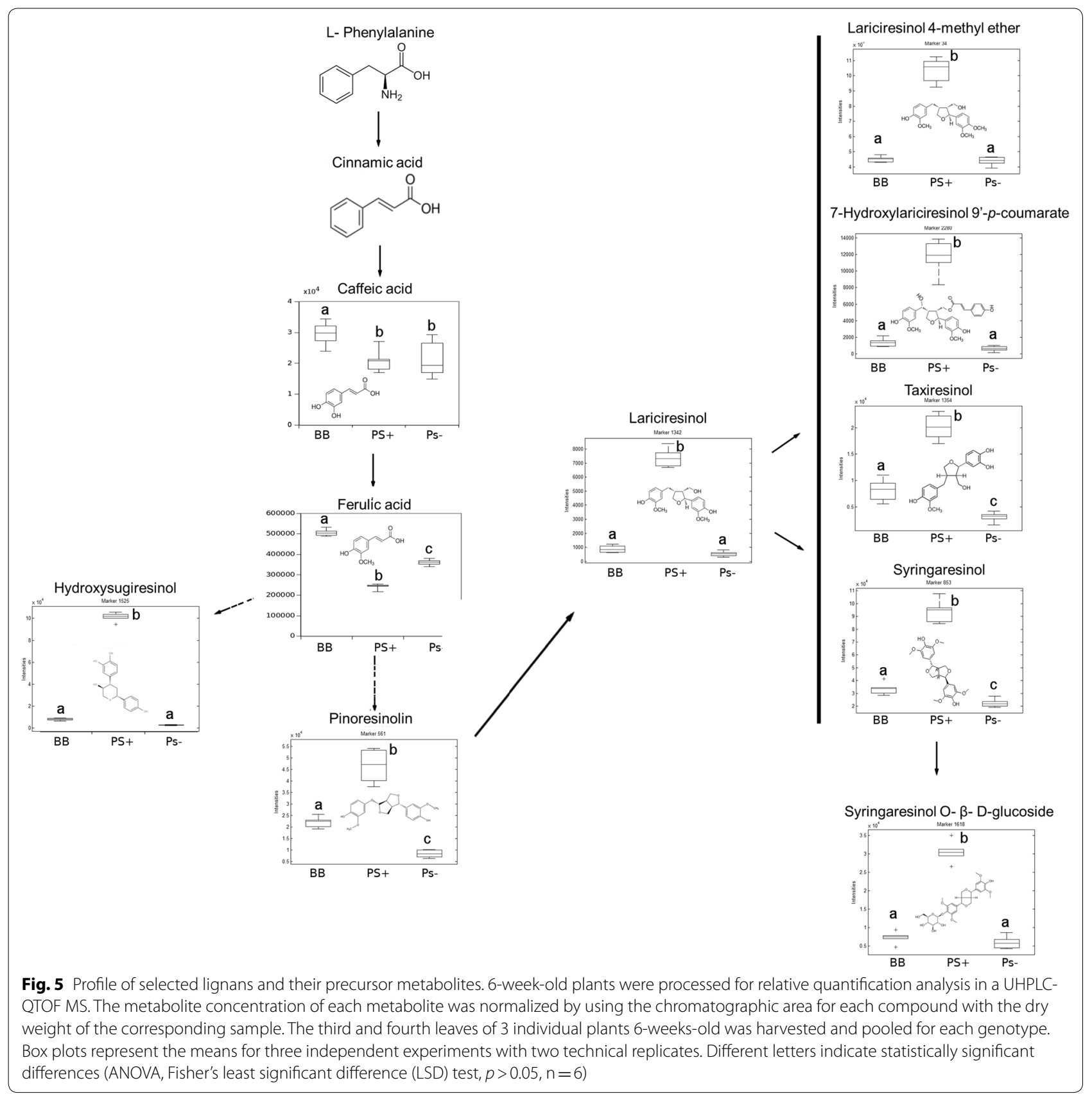

relevant identified pathways comprised compounds participating in the $\mathrm{ABC}$ transporter pathway. Scranton et al. [47] have reported incremental accumulation of monolignol biosynthesis genes and flavonoids (anthocyanins) after injury in tomato leaves. The overexpression of PROSYS is described as the behaviour of a permanently injured plant, which releases PROSYS constitutively [19], and as shown in the present study, lignan and flavonoid biosynthesis are two of the pathways altered in PS+ plants.
Transcriptomic and proteomic analyses show that PROSYS overexpression has a considerable impact on the genes and proteins implicated in both oxidative stress and defence [33, 41], but there is no information regarding effects at a metabolomic level. Remarkably and unexpectedly, the overexpression of PROSYS was shown to induce SA-responsive genes and the jasmonic acid (JA) negative regulators JAZ1 and JAZ3 [33]. Our study corroborates this result at the metabolic level, where higher SA levels, but not JA levels, were found in PS+ plants (Fig. 6). This 

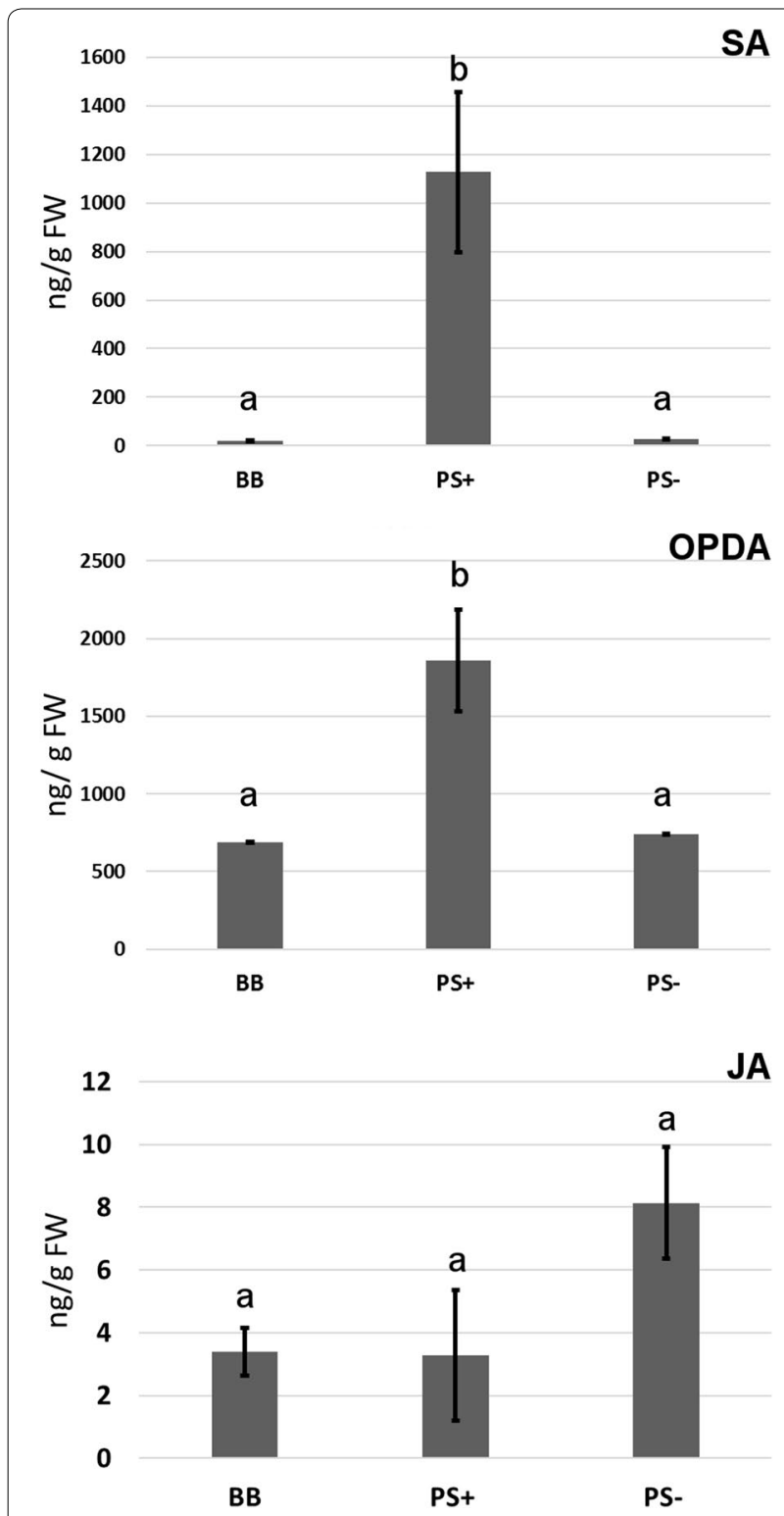

Fig. 6 Basal levels of the main defense-related hormones in the wild-type, overexpressor and antisense PROSYS plants. Leaves from six-week-old wild-type, PS+ and PS - plants were harvested for SA, OPDA and JA quantification. Samples from six independent experiments were used for the analysis. Different letters indicate statistically significant differences (ANOVA, Fisher's least significant difference (LSD) test, $p>0.05, n=6$ )

is an interesting finding, since the presence of PROSYS in plants has been associated with the enhancement of JA or its derivatives. In fact, PROSYS was shown to display enhanced PI1 and PI2 basal gene expression [19], and therefore, PS overexpressing lines have been used in multiple studies as JA overaccumulators. In our experiments, among the six independent biological replicates, we did not find more basal JA accumulation in PS+ plants; however, its precursor, OPDA, accumulated significantly. This observation calls for a reconsideration of PS+as a JA overaccumulator.

To confirm whether the accumulation of lignans is a SYS-dependent effect, BB wild-type tomato plants were treated exogenously with the peptide SYS, and metabolomics analysis under the same conditions as described above was performed. SYS applied exogenously resulted in strong impacts on the lignin, $A B C$ transporters-substrate compound, tyrosine metabolism and phenylpropanoid biosynthesis pathways in the SYS-treated plants compared with water-treated controls (Additional file 6: Table S3). This observation confirms and highlights a strong metabolomic overlap between SYS-treated and PS+ overexpressing plants. Further studies are needed to elucidate the exact relation between SYS and lignan metabolism.

\section{Conclusions}

Peptides are attracting more and more attention due to their involvement in the defence processes, although detection and quantification are challenging issues, since peptide levels might be very low. Thus, the combination of very sensitive instrumentation and methods with reduced sample manipulation are desirable to get a precise and accurate quantification of the peptide of interest. PS+ plants accumulate endogenous SYS, leading to metabolic changes that may affect other physiological responses. The major changes observed in our study support an important regulatory role of SYS in the synthesis of metabolites implicated in cell wall structure. SYS quantification by an easy and simple method like ours allows the possibility of precisely exploring systemin regulation under stress conditions or upon plant elicitation, thereby establishing the role of this peptide in plant physiology.

\section{Methods}

Plant material and growth conditions

Wild-type tomato plants (Solanum lycopersicum), BetterBoy variety, and transgenic lines (overexpressor 35S::PROSYS and antisense of PROSYS gene) lines were provided by the Ryan laboratory and were referenced in McGurl et al., 1992 and 1994 [18, 19]. All plants were grown in a growth chamber under $16 \mathrm{~h}$ of light $(300 \mu \mathrm{E}$ $\mathrm{m}^{-2} \mathrm{~s}^{-1}$ ) at $26{ }^{\circ} \mathrm{C}$ and $8 \mathrm{~h}$ of dark at $22{ }^{\circ} \mathrm{C}$. The tomato seeds were sown in vermiculite, and when cotyledons were developed, the plantlets were transferred to $300 \mathrm{ml}$ pots with vermiculite:soil (1:1) mixture and watered three times a week with Long Ashton solution [48]. After 6 weeks, the germinated samples were harvested and placed in $-80^{\circ} \mathrm{C}$ until analysis. 


\section{SYS treatment}

Seeds of the wild-type plants of BetterBoy cultivar were sown in jiffy-7 pots. Plants were treated by soil drenching with $10 \mathrm{nM}$ (as final concentration) of the peptide SYS (http://www.genscript.com/) 48 h before of harvesting. Leaves were harvested after 6 weeks and placed in $-80{ }^{\circ} \mathrm{C}$ until analysis.

\section{Reagents and standards}

Supergradient HPLC-grade methanol and acetonitrile were purchased from Scharlab (ME 0306 and AC 0331, respectively). Formic acid was obtained from J.T. Baker (Deventer, Holland, 6037). Labelled and non-labelled peptides were purchased from Genscript. Lignan standards were purchased in Sigma.

\section{Liquid chromatography-tandem mass spectrometry (LC- MS/MS) for SYS analysis}

High-performance liquid chromatography (HPLC) was performed by using a Waters Xevo TQ-S. Aliquots of $20 \mu \mathrm{l}$ were injected into the system through a reversed column Aeris PEPTIDE $3.6 \mu \mathrm{XB}-\mathrm{C} 18(150 \times 4.6 \mathrm{~mm})$ from Phenomenex, with a flow rate of $0.3 \mathrm{ml} \mathrm{min}^{-1}$. SYS was eluted with a flow of a gradient of $\mathrm{ACN}$ (organic phase) and Milli-Q water containing $0.1 \%$ of $\mathrm{HCOOH}$ (aqueous phase), starting with 5:95 (v/v), reaching 35:65 $(\mathrm{v} / \mathrm{v})$ linearly over $10 \mathrm{~min}$ and plateauing at 95:5 (v/v) 1 min later. The gradient was kept in isocratic conditions for $1 \mathrm{~min}$ before the column was left to equilibrate for $3 \mathrm{~min}$ in order to reach initial conditions, for a total of 15 min per sample.

The effluents originating from the HPLC were introduced into a triple quadrupole mass spectrometer (Xevo TQS, Waters Micromass, Manchester, UK) equipped with T-Wave devices and an ESI interface operated in positive mode. The cone and desolvation gas was nitrogen. The nebulizer gas flow was set to $250 \mathrm{~L} \mathrm{~h}^{-1}$ and the desolvation gas flow at $1200 \mathrm{~L} \mathrm{~h}^{-1}$. For operation in tandem MS/MS mode, the collision gas was pure $99.995 \%$ argon (Praxair, Madrid, Spain), with a pressure of $4 \times 10^{-3} \mathrm{mbar}$ in the collision cell. The desolvation gas temperature was $650{ }^{\circ} \mathrm{C}$, the source temperature was set at $150^{\circ} \mathrm{C}$, and capillary voltage was $3.2 \mathrm{kV}$. The mass spectrometer was set in multiple reaction monitoring (MRM) mode and the data were acquired and processed using the MassLynx $\mathrm{v}$ 4.1 software (Waters, Manchester, UK).

\section{LC-ESI full scan mass spectrometry (Q-TOF instrument)}

Freeze-dried leaves ( $30 \mathrm{mg}$ per sample) were homogenized on ice in $1 \mathrm{ml}$ of $\mathrm{MeOH}: \mathrm{H}_{2} \mathrm{O}(10: 90)$ containing $0.01 \%$ of $\mathrm{HCOOH}$ with metal balls $(2 \mathrm{~mm} ø)$. The homogenates were centrifuged at $14000 \mathrm{rpm}$ for $20 \mathrm{~min}$ at $5{ }^{\circ} \mathrm{C}$. The supernatant was recovered and filtrated through $0.2 \mu \mathrm{m}$ of regenerated cellulose filters (Teknokroma). An aliquot $(20 \mu \mathrm{l})$ of the filtered extract was used for LC-MS analysis. Full metabolomics profiling was carried out by nontargeted analysis using an Acquity UPLC system (Waters, Milford, MA, USA) interfaced to a hybrid quadrupole time-of-flight mass spectrometer (Q-TOF MS Premier). The LC separation was performed with a Kinetex C18 analytical column, $1.7 \mu \mathrm{m}$ particle size, $50 \mathrm{~mm} \times 2.1 \mathrm{~mm}$ (Phenomenex). Elution of metabolites was performed using a gradient of methanol and water, both containing $0.01 \%$ of $\mathrm{HCOOH}$. The gradient started with an aqueous solvent al $95 \%$ and a flow of $0.3 \mathrm{ml} \mathrm{min} \mathrm{m}^{-1}$. The gradient reached $50 \%$ of aqueous solvent at $8 \mathrm{~min}$, increasing the level of organic solvent to $95 \%$ at $12 \mathrm{~min}$. The gradient was kept in isocratic conditions for $1 \mathrm{~min}$ and later returned to initial conditions in $2 \mathrm{~min}$. The column could equilibrate for $3 \mathrm{~min}$, for a total of $22 \mathrm{~min}$ per sample. The library of compounds used for straight compound identification as well as the Q-TOF MS parameters were set as described by Gamir et al. (2014) [49].

\section{Liquid chromatography-tandem mass spectrometry (LC- MS/MS) for hormone analysis}

Plant samples were stored at $-80{ }^{\circ} \mathrm{C}$ and approximately $350 \mathrm{mg}$ of fresh material per sample was transferred into $2 \mathrm{ml}$ microcentrifuge tubes. Ultrapure water (Millipore, www.merckmillipore.com) with a solution of internal standards was added to the microtubes (SA-d5 and dhJA (Sigma-Aldrich)). The contents of the tubes were homogenized with glass beads $(2 \mathrm{~mm} ø)$, and extractions were performed in a mixer mill at a frequency of $30 \mathrm{~Hz}$ for $3 \mathrm{~min}$. The tubes were centrifuged at $13.000 \mathrm{rpm}$ for $30 \mathrm{~min}$. Supernatants were adjusted to a $\mathrm{pH}$ of 2.5 with acetic acid $50 \%(\mathrm{v} / \mathrm{v})$, and extractions were partitioned twice against diethyl ether. Organic fractions were concentrated to dryness in a centrifugal evaporator (Speedvac) at room temperature. The samples were resuspended in $1 \mathrm{ml}$ of $\mathrm{H}_{2} \mathrm{O} / \mathrm{MeOH}$ (90:10), leading to a 100-ng ml final concentration of the internal standards. The columns used for chromatographic separation were the same as described above, and the chromatographic conditions and TQD parameters used were described by Gamir et al. (2014) [49].

\section{Full-scan data analysis}

Raw data were transformed to.cdf files using the DataBridge package provided by the Masslynx 4.1. Signals derived from ESI (+) and ESI (-) were processed separately. Peak peaking, grouping and signalling corrections were processed with $\mathrm{R}$ software for statistical computing using the XCMS package for relative quantification [50]. Partial least-squares (PLS), heatmap construction and clustering were performed with MetaboAnalyst 3.0 [40]. 
The Kruskal-Wallis test $(p<0.05)$ was applied to show differences between conditions. For signal identification, MarVis Pathway software was used [42]. Syringaresinol O-beta-D-glucoside, taxiresinol, epysyringaresinol, lariciresinol, and pinoresinol standards were used as an internal library for full identification.

\section{RNA extraction and RT-qPCR analysis}

Measurements in gene expression were performed by quantitative RT-qPCR using RNA samples extracted from third and fourth true leaves. The process of RNA extraction was adapted from Valledor et al. [51]. Samples were treated with DNAse I (Takara) following the manufacturer' instructions. To obtain cDNA, $1.5 \mu \mathrm{g}$ of RNA was annealed to oligo-dTs, and retrotranscription was performed with a PrimeScript RT reagent kit (Perfect real-time) from Takara. RT-qPCR was conducted using Maxima SYBR Green/ROX qPCR (Thermo Scientific) on a StepOne instrument (Applied Biosystems). For optimum amplification efficiency, a standard curve through serial dilutions of cDNA was constructed. Specificity of RT-qPCR amplification was tested by looking for a single peak in the melting temperature curve analysis. Relative quantification of mRNA levels was calculated using the comparative $2_{\mathrm{T}}^{-\Delta \Delta C}$ method [52]. For normalization of expression values, two housekeeping genes were used: the tomato elongation factor $E F-1$ ( $f w-5^{\prime}$-GATTGGTGGTATTGGAACTGTC-3'; rev- $5^{\prime}$-AGCTTCGTGGTGCATCTC- $3^{\prime}$ ) and the tomato ACT-52 gene ( $f w$ - 5'-CACCATTGGGTCTGAGCG-3'; rev- 5'-GGGCGACAACCTTGATCT- $\left.3^{\prime}\right)$. Relative expression data between the studied gene PROSYS ( $f w$ - $5^{\prime}$-AATTTGTCT CCCGTTAGA-3'; rev- 5'-AGCCAAAAGAAAGGAAGCAAT- $3^{\prime}$ ) and the housekeeping genes were calculated from the differences in threshold cycle $(\Delta \mathrm{Ct})$.

\section{Statistical analyses}

All statistical analyses were conducted with Statgraphics Centurion software for the ANOVA, with post hoc and $t$ test analysis. The $\mathrm{xcms}$ package in the $\mathrm{R}$ software version 3.1.2 was used for these analyses. All experiments were repeated at least three times, unless otherwise noted.

\section{Additional files}

Additional file 1: Figure S1. Positive precursor ion and MS/MS product ion mass spectra for SYS. SYS standards were infused into the MS analyser at the concentration of $1 \mathrm{mg} \mathrm{I}^{-1}$. (a) Parental ions for SYS; (b) spectrum fragmentation of $[\mathrm{SYS}+4 \mathrm{H}]^{4+}$.

Additional file 2: Figure S2. Optimized fragmentation spectrum of SYS and SYS*. The product ions obtained by ESI (+) corresponding to 503.3 and 505.1 were fragmented to obtain the fragmentation spectra for SYS and SYS* and optimized for the transitions to 143.1 and 148.1 respectively.

Additional file 3: Figure S3. HPLC-MS/MS chromatograms of labelled SYS. Chromatograms obtained with $100 \mathrm{ng} \mathrm{ml}^{-1}$ of pure labelled SYS* dissolved in $\mathrm{H}_{2} \mathrm{O}$ : ACN (9:1) $\mathrm{v} / \mathrm{V}$ in the same chromatographic conditions used for SYS standard.

Additional file 4: Table S1. Tentative identification of lignans accumulated in PS+. Tentative candidates of lignans attributed to the endogenous SYS present in PS+ with their respective product ions in ESI (-). Identification and pathway assignments were done using the MarVis 2.0 software and an internal library, referred-to level 3 [43].

Additional file 5: Table S2. Relevant pathways and compounds under SYS control. List of compounds that show higher level intensities in PS+, and lower ones in PS - respect to BB and PS+. All the masses presented in the table have been annotated at a tentative level, although in some of them a further identification by using fragmentation spectrum has been performed. Abbreviations: $\mathrm{fs}$, identification by exact mass and fragmentation spectrum level 2 of identification [43]; ti, is a tentative identification of the compound referred-to level 3 [43].

Additional file 6: Table S3. Tentative identification of lignans accumulated by exogenous SYS. Tentative candidates for lignans accumulated after two days of SYS application at $10 \mathrm{nM}$ of final concentration applied in roots, in ESI (-). Identification and pathway assignments were done using the MarVis 2.0 software and an internal library (level 3 of identification [43]).

\section{Abbreviations}

PROSYS: Prosystemin peptide; SYS: Systemin peptide; PS+: Overexpressor of Prosystemin; PS-: Antisense mutant of Prosystemin; MAMP: Microbe associated molecular pattern; DAMP: Damage associated molecular pattern; PTI: Pathogen Associated Molecular Pattern-triggered Immunity; AtPeps: Peptides in Arabidopsis; PEPR1 and PEPR2: Arabidopsis peptide receptor PEPRECEPTOR 1; ZmPep: Peptides in Zea mays; PI: Proteinase inhibitor; HypSys: Hydroxyproline-rich systemins; MRM: Multiple reaction monitoring; ESI (+): Electrospray ionization in positive mode; ESI (-): Electrospray ionization in negative mode.

\section{Authors' contributions}

VP and VF designed the research; VP, VF and PSB performed the experiments; VP analysed the data of non-targeted analysis of the plant material and validate the analytical method. PSB contributed with gene expression of PROSYS gene; JG performed the hormonal analysis. VP and MJP wrote the manuscript.

\section{Author details}

${ }^{1}$ Associated Unit EEZ-UJI. Metabolic Integration and Cell Signaling Laboratory, Plant Physiology Section, Universitat Jaume I, Associated Unit to the CSIC, Castellón de la Plana, Castellón, Spain. ${ }^{2}$ Department of Soil Microbiology and Symbiotic Systems, Estacion Experimental del Zaidin (CSIC), Granada, Spain.

\section{Acknowledgements}

We thank the SCIC of the Universitat Jaume I and Dr. Cristian Vicent Barreda for its technical support.

\section{Competing interests}

The authors declare that they have no competing interests.

\section{Availability of data and materials}

KEGG Solanum Lycopersium database: http://www.genome.jp/kegg-bin/ show_organism?menu_type=pathway_maps\&org=sly. Metlin databe available at: https://xcmsonline.scripps.edu/. MassBank database: http://www. massbank.jp/QuickSearch.html.

Consent for publication

Not applicable. 
Ethics approval and consent to participate

Not applicable.

\section{Funding}

This work was financially supported by the Plan de Promoción de la Investigación de la Universitat Jaume I P1- 1B2015-33, the Spanish Ministry MINECO AGL2015-64990-C2-2-R and the Generalitat Valenciana project AICO/2016/029.

\section{Publisher's Note}

Springer Nature remains neutral with regard to jurisdictional claims in published maps and institutional affiliations.

Received: 2 November 2017 Accepted: 20 April 2018

Published online: 26 April 2018

\section{References}

1. Conrath U, Thulke O, Katz V, Schwindling S, Kohler A. Priming as mechanism in induced systemic resistance of plants. Eur J Plant Pathol. 2001;107:113-9.

2. Pastor V, Luna E, Mauch-Mani B, Ton J, Flors V. Primed plants do not forget. Environ Exp Bot. 2013;94:46-56.

3. Martinez-Medina A, Flors V, Heil M, Mauch-Mani B, Pieterse CMJ, Pozo MJ, Ton J, van Dam NM, Conrath U. Recognizing plant defense priming. Trends Plant Sci. 2016:21:818-22.

4. Van Wees SC, Van der Ent S, Pieterse CM. Plant immune responses trigguered by beneficial microbes. Curr Opin Plant Biol. 2008;1 1:443-8.

5. Breen S, Solomon PS, Bedon F, Vincent D. Surveying the potential of secreted antimicrobial peptides to enhance plant disease resistance. Front Plant Sci. 2015:6:900.

6. Boller T, Felix G. A renaissance of elicitors: perception of microbe-associated molecular patterns and danger signals by pattern-recognition receptors. Ann Rev Plant Biol. 2009;60:379-406.

7. Flury P, Klauser D, Schulze B, Boller T, Bartels S. The anticipation of danger: microbe-associated molecular pattern perception enhances AtPeptriggered oxidative burst. Plant Phys. 2013:161:2023-35.

8. Albert M. Peptides as triggers of plant defence. J Exp Bot. 2013;64:5269-79.

9. Bartels S, Boller T. Quo vadis, Pep? Plant elicitor peptides at the crossroads of immunity, stress, and development. J Exp Bot. 2015;66:5183-93.

10. Huffaker A, Pearce G, Ryan CA. An endogenous peptide signal in Arabidopsis activates components of the innate immune response. Proc Natl Acad Sci USA. 2006:103:10098-103.

11. Krol E, Mentzel T, Chinchilla D, Boller T, Felix G, Kemmerling B, Postel S, Arents M, Jeworutzki E, Al-Rasheid KA, Becker D, Hedrich R. Perception of the Arabidopsis danger signal peptide1 involves the pattern recognition receptor AtPEPR1 and its close homologue AtPEPR2. J Biol Chem. 2010;285:13471-9.

12. Huffaker A, Dafoe NJ, Schmelz EA. ZmPep1, an ortholog of Arabidopsis elicitor Peptide 1, regulates maize innate immunity and enhances disease resistance. Plant Phys. 2011;155:1325-38

13. Huffaker A, Pearce G, Veyrat N, Erb M, Turlings TC, Sartor R, Shen Z, Briggs SP, Vaughan MM, Alborn HT, Teal PE, Schmelz EA. Plant elicitor peptides are conserved signals regulating direct and indirect antiherbivore defense. Proc Natl Acad Sci USA. 2013;110:5707-12.

14. Pearce G, Strydom D, Johnson S, Ryan CA. A polypeptide from tomato leaves induces wound-inducible proteinase inhibitor proteins. Science. 1991:253:895-7.

15. Green T, Ryan CA. Wound-induced proteinase inhibitor in plant leaves: a possible defense mechanism against insects. Science. 1972;175:775-6.

16. Bishop PD, Pearce G, Bryant JE, Ryan CA. Isolation and characterization of the proteinase inhibitor-inducing factor from tomato leaves-identity and activity of polygalacturonide and oligogalacturonide fragments. J Biol Chem. 1984;259:3172-7

17. Farmer EE, Ryan CA. Interplant communication-airbone methyl jasmonate induces synthesis of proteinase-inhibitors in plant-leaves. Proc Natl Acad Sci USA. 1990:87:7713-6.
18. McGurl B, Pearce G, Orozco-Cardenas M, Ryan CA. Structure, expression and antisense inhibition of the systemin precursor gene. Science. 1992;255:1570-3.

19. McGurl B, Orozco-Cardenas M, Perace G, Ryan CA. Overexpression of the prosystemin gene in transgenic tomato plants generates a systemic signal that constitutively induces proteinase inhibitor synthesis. Proc Natl Acad Sci USA. 1994;91:9799-802.

20. Narváez-Vásquez J, Orozco-Cárdenas ML, Ryan CA. Systemic wound signalling in tomato leaves is cooperatively regulated by systemin and hydroxyproline-rich glycopeptide signals. Plant Mol Biol. 2007;65:711-8.

21. Hind SR, Malinowski R, Yalamanchili R, Stratmann W. Tissue-type specific systemin perception and the elusive systemin receptor. Plant Signal Behav. 2010;5:42-4

22. Ohyama K, Ogawa M, Matsubayashi Y. Identification of a biologically active, small, secreted peptide in Arabidopsis by in silico gene screening, followed by LC-MS-based structure analysis. Plant J. 2008;55:152-60.

23. Du F, Bai Y, Bai Y, Liu H. Quantitative detection of trace systemins in Solanaceous plants by immunoaffinity purification combined with liquid chromatography/electrospray quadrupole time-of-flight mass spectrometry. Anal Chem. 2010;82:9374-83.

24. Bronsema KJ, Bischoff R, van de Merbel NC. High sensitivity LC-MS/MS quantification of peptides and proteins in complex biological samples: the impact of enzymatic digestion and internal standard selection on method performance. Anal Chem. 2013;85:9528-35.

25. Wang Y, Chantreau M, Sibout R, Hawkins S. Plant cell wall lignification and monolignols metabolism. Front Plant Sci. 2013:4:220.

26. Bagniewska-Zadworna A, Barakat A, Łakomy P, Smoliński DJ, Zadworny M. Lignin and lignans in plant defence: insight from expression profiling of cinnamyl alcohol dehydrogenase genes during development and following fungal infection in Populus. Plant Sci. 2014;229:111-21.

27. Rauh M. LC-MS/MS for protein and peptide quantification in clinical chemistry. J Chromatogr B. 2012;877:2198-207.

28. Stokvis $\mathrm{E}$, Rosing $\mathrm{H}$, Beijnen JH. Stable isotopically labeled internal standards in quantitative bioanalysis using liquid chromatography/ mass spectrometry: necessity or not? Rapid Commun Mass Spectrom. 2005;19:401-7.

29. Du F, Bai Y, Bai Y, Liu H. Mass spectrometric fragmentation mechanism and chromatographic retention for polypeptide hormones-systemin and its analogs. Chin J Anal Chem. 2011;39:1147-52.

30. Su C, Liu C, Chen J, Chen Z, He Z. Simultaneous determination of zeatin and systemin by coupling graphene oxide-protected aptamers with cataIytic recycling of DNase I. Sens Actuators B. 2016:230:442-8.

31. Li L, Li C, Lee Gl, Howe GA. Distinct roles for jasmonate synthesis and action in the systemic wound response of tomato. Proc Natl Acad Sci USA. 2002;99:6416-21.

32. Li C, Zhao J, Jiang H, Wu X, Sun J, Zhang C, Wang X, Lou Y, Li C. The wound response mutant suppressor of prosystemin-mediated responses 6 (spr6) is a weak allele of the tomato homolog of CORONATINE-INSENSITIVE1 (COI1). Plant Cell Physiol. 2006;47:653-63.

33. Coppola M, Corrado G, Coppola V, Cascone P, Martinelli R, Digilio MC, Pennacchio F, Rao R. Prosystemin overexpression in tomato enhances resistance to different biotic stresses by activating genes of multiple signaling pathways. Plant Mol Biol Rep. 2015;33:1270-85.

34. Corrado G, Agrelli D, Rocco M, Basile B, Marra M, Rao R. Systemin-induci ble defence agaisnt pest is costly in tomato. Biol Plant. 2011;55:305-11.

35. Beloshistov RE, Dreizler K, Galiullina RA, Tuzhikov Al, Serebryakova MV, et al. Phytaspase-mediated precursor procesing and maturation of the wound hormone systemin. New Phytol. 2017. https://doi.org/10.1111/ nph.14568.

36. Kettenbach AN, Rush J, Gerber SA. Absolute quantification of protein and post-translational modification abundance with stable isotope-labeled synthetic peptides. Nat Protoc. 2011;6:175-86.

37. El Oirdi M, El Rahman TA, Rigano L, El Hadrami A, Rodriguez MC, Daayf F, Vojnov A, Bouarab K. Botrytis cinerea manipulates the antagonistic effects between pathways to promote disease development in tomato. Plant Cell. 2011:23:2405-21.

38. Fernie AR, Aharoni A, Willmitzer L, Stitt M, Tohge T, Kopka J, Carroll AJ, Saito K, Fraser PD, DeLuca V. Recommendations for reporting metabolite data. Plant Cell. 2011;23:2477-82. 
39. Kaever A, Lingner T, Feussner K, Göbel K, Feussner I, Meinicke P. MarVis: a tool for clustering and visualization of metabolic biomarkers. BMC Bioinf. 2009;10:92. https://doi.org/10.1186/1471-2105-10-92.

40. Xia J, Sinelnikov IV, Han B, Wishart DS. MetaboAnalyst 3.0-making metabolomics more meaningful. Nucleic Acids Res. 2015;43(Web Server issue):W251-7.

41. Rocco M, Corrado G, Arena S, D'Ambrosio C, Tortiglione C, Sellaroli S, Marra M, Rao R, Scaloni A. J. Proteomics. 2008;71:176-85.

42. Kaever A, Landesfeind M, Feussner K, Mosblech A, Heilmann I, Morgenstern B, Feussner I, Meinicke P. MarVis-Pathway: integrative and exploratory pathways analysis of non-targeted metabolomics data. Metabolomics. 2015;11:764-77.

43. Schymanski EL, Jeon J, Gulde R, Fenner K, Ruff M, Singer HP, Hollender J. Identifying small molecules via high resolution mass spectrometry: communicating confidence. Environ Sci Technol. 2014;48:2097-8.

44. Umezawa T. Diversity in lignan biosynthesis. Phytochem Rev. 2003;2:371-90.

45. Kretzschmar T, Burla B, Lee $Y$, Martinoia E, Nagy R. Functions of ABC transporters in plants. Essays Biochem. 2011;50:145-60.

46. Yazaki K. ABC transporters involved in the transport of plant secondary metabolites. FEBS Lett. 2006;580:1183-91.
47. Scranton MA, Fowler JH, Girke T, Walling LL. Microarray analysis of tomato's early and late wound response reveals new regulatory targets for leucine aminopeptidase A. PLoS ONE. 2013;8:e77889.

48. Hewitt EJ. Sand and water culture methods used in the study of plant nutrition. In: Technical communication, vol. 22. London: Commonwealth Agriculture Bureau; 1966.

49. Gamir J, Pastor V, Kaever A, Cerezo M, Flors V. Targeting novel chemical and constitutive primed metabolites against Plectosphaerella cucumerina. Plant J. 2014;78:227-40.

50. Smith CA, Want EJ, O'Maille G, Abagyan R, Siuzdak G. XCMS: processing mass spectrometry data for metabolite profiling using nonlinear peak alignment, matching, and identification. Anal Chem. 2006;78:779-87.

51. Valledor L, Escandón M, Meijón M, Nukarinen E, Cañal MJ, Weckwerth W. A universal protocol for the combined isolation of metabolites, DNA, long RNAs, samll RNAs and proteins from plants and microorganisms. Plant J. 2014;79:173-80.

52. Livak KJ, Schmittgen T. Analysis of relative gene expression data using real-time quantitative PCR and the method. Methods. 2001:25:402-8.
Ready to submit your research? Choose BMC and benefit from:

- fast, convenient online submission

- thorough peer review by experienced researchers in your field

- rapid publication on acceptance

- support for research data, including large and complex data types

- gold Open Access which fosters wider collaboration and increased citations

- maximum visibility for your research: over 100M website views per year

At BMC, research is always in progress.

Learn more biomedcentral.com/submissions 